\title{
The alcohol-deprivation effect in monkeys
}

\author{
J. D. SINCLAIR \\ University of Oregon, Eugene, Ore. 97403
}

One stumptail and four rhesus monkeys were given free access to solutions of ethyl alcohol (increasing from $7 \%$ to $20 \% \mathrm{v} / \mathrm{v}$ ) for 22 days. A subsequent 6 days without alcohol produced a significant increase in alcohol consumption when it was first made available again. Such an "alcohol-deprivation effect" is similar to that previously seen with rats. Unlike the rats, the monkeys frequently appeared to drink to intoxication.

Various strains of rats have been found to increase temporarily their intake of ethyl alcohol following a 1 -week interruption in their access to it (Sinclair \& Senter, 1967, 1968; Sinclair, 1971). This behavior has been designated the "alcohol-deprivation effect" (ADE). In the present experiment, monkeys were tested to see if they, too, would show an ADE. METHOD

The Ss were one stumptail and three rhesus male monkeys. [Data from an additional rhesus (Alte) were lost, due to his pulling the plug out of his alcohol bottle on Day 29.] Each had been used in a wide variety of learning experiments in previous years, but they had not been used during the year preceding this study. They had had no previous experience with alcohol. The stumptail, Clarence, had had electrodes implanted in his forebrain for 2 months, 3 years prior to this study. The initial weights were: Charlie, $8.8 \mathrm{~kg}$; Lee, $11.8 \mathrm{~kg}$; Zooey, $10.2 \mathrm{~kg}$; and Clarence, $14.3 \mathrm{~kg}$. They showed virtually no changes in weight during the experiment. They all were approximately 8 years old.

Alcohol solutions were available from $250-\mathrm{ml}$ bottles with rubber stoppers and metal spigots.

Water was continually available from a fountain in each cage, but the quantity consumed could not be measured. All data were, therefore, converted to the milliliters of absolute alcohol consumed daily by each monkey, divided by his weight in kilograms.

The routine treatment of the monkeys was not altered. The monkeys were removed approximately once a week from their home cages, for 3 to $4 \mathrm{~h}$, for cleaning of the room, and alcohol was not available to them during these times. They were fed their regular diet of Purina monkey chow and fruit.

All monkeys were initially given a $7 \% \mathrm{v} / \mathrm{v}$ solution of ethanol and then were progressively switched to concentrations of $10 \%, 12 \%, 15 \%$, and eventually $20 \% \mathrm{v} / \mathrm{v}$. If an animal emptied his bottle in a single day, the bottle was refilled and he was given an additional $20 \mathrm{~min}$ to drink from it.

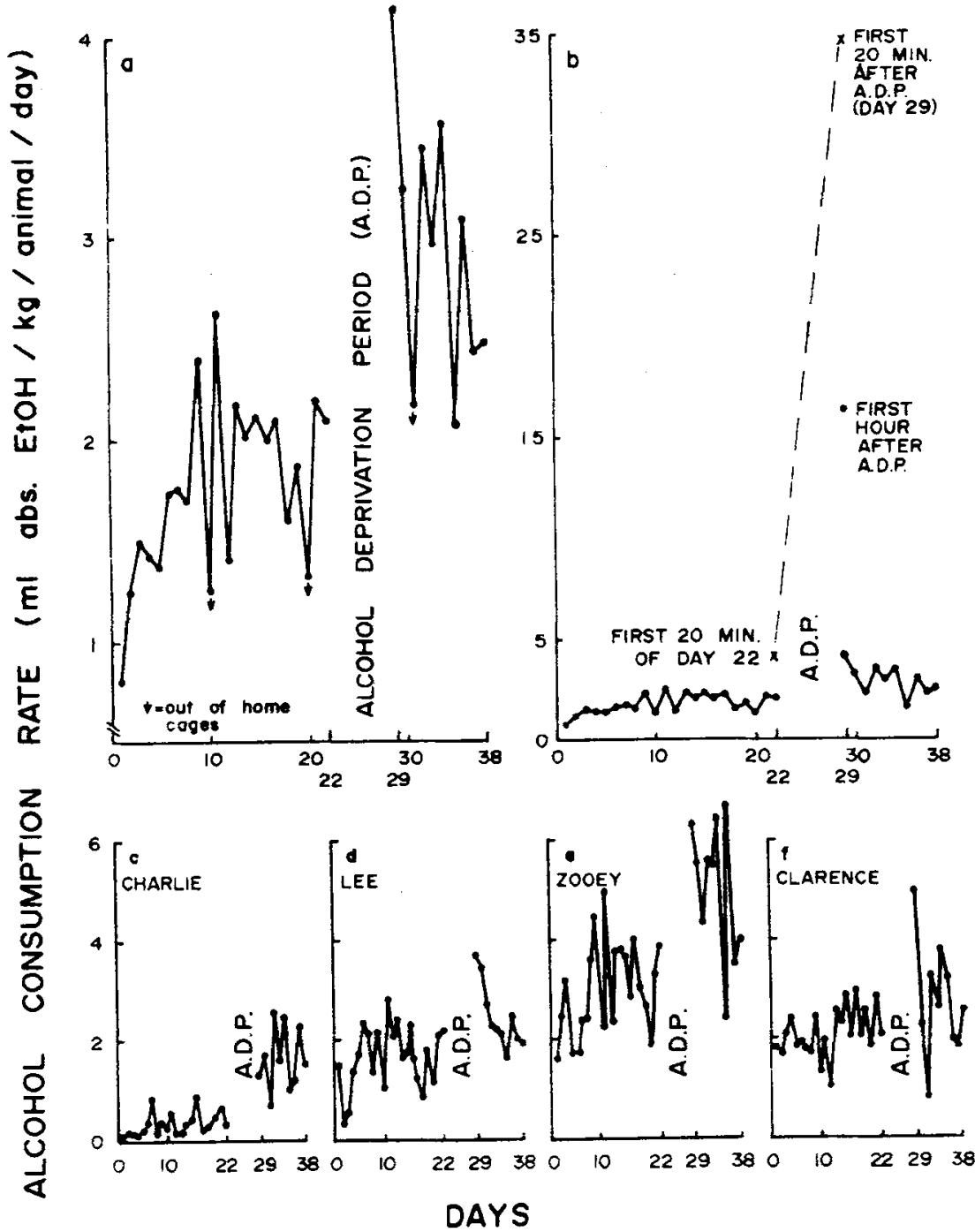

Fig. 1. (a) The mean daily rate of alcohol consumption for the four monkeys. Notice the increase during the initial access period (Days 1.22) and the large, but temporary, increase immediately following the alcohol-deprivation period (ADP). (b) During the first $20 \mathrm{~min}$ after alcohol was again made available (on Day 29, following the ADP), the monkeys consumed it at such a rapid rate that had they continued drinking at this rate for $24 \mathrm{~h}$, they would have drunk nearly $35 \mathrm{ml}$ of absolute alcohol $/ \mathrm{kg} / \mathrm{animal}$. This is much higher than the alcohol consumption rate during a similar $20-\mathrm{min}$ interval not preceded by alcohol deprivation (i.e., on Day 22, immediately after bottle filling). It is also much higher than the mean daily rate of alcohol consumption, shown in Frame a and shown again as the solid line at the bottom of Frame b. (c-f) Individual alcohol consumption records. 
RESULTS AND DISCUSSION

Each of the four animals drank more alcohol on the first day following deprivation (Day 29) than on any of the 22 prior days of initial access (see Fig. 1a). Their mean alcohol consumption on Day 29 was significantly higher than on the last day before deprivation (No. 22) $(t=4.77, d f=3, p<.02)$.

Two of the monkeys, Lee (Fig. 1d) and Clarence (Fig. 1f), showed patterns of consumption similar to those presented by rats: after drinking a massive quantity of alcohol on the first postdeprivation day, they gradually decreased their intake, eventually returning to their level before deprivation. Zooey (Fig. 1e) showed a somewhat similar pattern, except for 2 days of unexpected high consumption. Charlie, who was the most gentle and least aggressive monkey, differed from the others in a number of ways. Before deprivation, his alcohol consumption was markedly lower than the other monkeys'. After deprivation, he did increase his alcohol intake, but unlike the others, he remained at the higher level.

When alcohol is first returned to rats, following deprivation, they immediately begin drinking it, in bouts up to $10 \mathrm{ml}$, sometimes lasting over 5 min (Sinclair, 1971). Figure 1b illustrates the corresponding massive alcohol intake by the monkeys during the first $20 \mathrm{~min}$ after the resumption of access to alcohol. This is compared with the consumption during the first $20 \mathrm{~min}$ after bottle filling on Day 22 . (The bottles had been filled twice on Day 21, to insure that all the monkeys had alcohol remaining when they were refilled on Day 22.)

A similar heavy intake of alcohol was often seen during the first $20 \mathrm{~min}$ after bottle refilling, if the monkey had emptied his bottle the previous day (i.e., after a self-induced alcohol-deprivation period of only a few hours.) Zooey once drank $170 \mathrm{ml}$ of $15 \%$ alcohol solution in $20 \mathrm{~min}$ and, consequently, was barely able to remain upright for the next several hours. All of the monkeys, except Charlie, frequently drank to the point of showing signs of intoxication, such as lack of coordination, resting their heads against the sides of the cages, lying in corners, and not responding to humans or food. This intoxication was reported by the caretakers and correlated well with the quantities of alcohol consumed. The monkeys' drinking to intoxication was surprising, since, with the possible exception of hedgehogs (Arvola \& Fosander, 1961), the only creatures previously reported to show this rather irrational behavior, completely voluntarily, were humans.

ARVOLA A Comparison between water and alcohol consumption in six animal species in free-choice experiments. Nature, 1961. $191,819-820$.

SINCLAIR, J. D. The influence of various factors on the alcohol-deprivation effect. Quarterly Journal of Studies on Alcohol. 1971 , in press.

SINCLAIR, J. D., \& SENTER, R. J. Increased preference for ethanol in rats following alcohol deprivation. Psychonomic Science, 1967, 8, 11-12.

SINCLAIR J D. \& SENTER R J Development of an alcohol-deprivation effect in rats. Quarterly Journal of Studies on Alcohol, 1968, 29,863-867.

\section{CURRENT LITERATURE ABOUT DRUG EFFECTS ON BEHAVIOR}

ADAMS, P. M. (Department of Neurology and Psychiatry, University of Texas Medical Branch, Gaiveston, Tex. 77550), \& CRAWFORD, F. T. Spontaneous activity and water intake in the rat under the effects of scopolamine $\mathrm{HBr}$ and magnesium pemoline. Psychonomic Science, 1971, 23, 111-112.

BROWN, K. (Queen's University, Belf ast, Northern Ireland), \& WARBURTON, D. M. Attenuation of stimulus sensitivity by scopolamine. Psychonomic Science, 1971, 22, 297-298.

CHISHOLM, D. C. (University of Massachusetts, Amherst, Mass. 01002), COUCH, J. V., \& MOORE, J. W. Chlordiazepoxide and aversive conditioning: Effects of acquisition and performance of the conditioned nictitating membrane response in the rabbit. Psychonomic Science, 1971, 23, 203-204.

COULSON, G. E. (York University, Toronto, Ontario, Canada), KOFFER, K. B., \& COULSON, V. Reinforcement of ethanol consumption in rats by an increase in the frequency of food-pellet delivery. Psychonomic Science,
$1971,23,103-104$

DEWSBURY, D. A. (University of Florida, Gainesville, Fla. 32601). Copulatory behavior of male rats following reserpine administration. Psychonomic Science, 1971, 22, 177-179.

ELIAS, M. F. (Center for the Study of Aging and Human Development, Duke University Medical Center, Durham, N.C. 27706), \& SIMMERMAN, S. J. Proactive and retroactive effects of diethyl ether on spatial discrimination learning in inbred mouse strains $\mathrm{DBA} / 2 \mathrm{~J}$ and C57BL/6J. Psychonomic Science, 1971, 22, 299-301.

GALLUP, G. G., JR. (Tulane University, New Orleans, La. 70118), NASH, R. F., \& BROWN, C. W. The effects of a tranquilizer on the immobility reaction in chickens: Additional support for the fear hypothesis. Psychonomic Science, 1971, 23, 127-128.

HARVEY, J. A. (University of Iowa, Iowa City, Iowa 52240), \& LINTS, C. E. Lesions in the medial forebrain bundle: Relationship between pain sensitivity and telencephalic content of serotonin. Journal of Comparative and
Physiological Psychology, 1971, 74, 28-36.

JOHNSON, J. T. (Memphis State University, Memphis, Tenn, 38116), STANTON, J. P., \& SEWELL, W. R. The effects of magnesium pemoline on Sidman avoidance behavior. Psychonomic Science, 1971, 23, 224-225.

PECK, J. W., \& NOVIN, D. (University of California, Los Angeles, Calif. 90024 ). Evidence that osmoreceptors mediating drinking in rabbits are in the lateral preoptic area. Journal of Comparative and Physiological Psychology, 1971, 74, 134-147.

PENROD, W. C., \& BOICE, R. (University of Missouri, Columbia, Mo. 65201). Effects of halothane anesthesia on the retention of a passive avoidance task in rats. Psychonomic Science, 1971, 23, 205-207.

POWELL, B. J. (Malcolm Bliss Mental Health Center and Washington University, St. Louis, Mo. 63104), \& HOPPER, D. J. Effects of strain differences and D-amphetamine sulfate on avoidance performance. Psychonomic Science, 1971, 22, 167-168. 